\title{
Upregulation of Bcl2 in NSCLC with acquired resistance to EGFR-TKI
}

\author{
HIO TENG CHEONG ${ }^{1}$, FEI XU ${ }^{2}$, CHI TUNG CHOY ${ }^{1}$, CONNIE WUN CHUN HUI ${ }^{1}$, \\ TONY SHU KAM MOK ${ }^{1}$ and CHI HANG WONG ${ }^{1}$
}

\author{
${ }^{1}$ Department of Clinical Oncology, Faculty of Medicine, The Chinese University of Hong Kong, \\ Hong Kong, SAR; ${ }^{2}$ Sun Yat-sen University Cancer Center, State Key Laboratory of Oncology in South China, \\ Collaborative Innovation Center for Cancer Medicine, Guangzhou, Guangdong 510000, P.R. China
}

Received January 29, 2016; Accepted January 13, 2017

DOI: $10.3892 / \mathrm{ol} .2017 .7377$

\begin{abstract}
Lung cancer has the highest incidence and mortality rate worldwide among all malignancy-associated mortalities, of which non-small cell lung cancer accounts for $80 \%$ of all cases. Resistance against epidermal growth factor receptor-tyrosine kinase inhibitors (EGFR-TKIs) develops following 8-12 months of disease progression, and is a critical issue. HCC827 cell lines with resistance to EGFR-TKIs were successfully screened. The half maximal inhibitory concentration values were 1,000-fold higher than the values for the parental HCC827 cell line, thereby demonstrating cross-resistance against the same family of TKIs. The expression of B-cell lymphoma 2 (Bcl2) was markedly increased in the resistant clones, as well as in the patient biopsies. The phosphatase and tensin homolog phosphoinositide 3-kinase signaling axis is a potential mechanism for acquiring resistance, and therefore targeting $\mathrm{Bcl} 2$ may be a useful strategy for further investigations.
\end{abstract}

\section{Introduction}

Lung cancer remains the global leading cause of malignancy-associated deaths, with the highest incidence and mortality rate, causing 1.6 million deaths worldwide in 2012 (1). Non-small cell lung cancer (NSCLC) accounts for $>80 \%$ of the cases and is often diagnosed at advanced stages of the disease. Platinum-based chemotherapy is the standard first-line systemic treatment; however, it has limited efficacy and significant toxicity (2-4). Over the previous decades, epidermal growth factor receptor (EGFR) has become a therapeutic target, as it triggers a signaling cascade that

Correspondence to: Dr Chi Hang Wong, Department of Clinical Oncology, Faculty of Medicine, The Chinese University of Hong Kong, 30-32 Ngan Shing Street, Hong Kong, SAR, P.R. China E-mail: eric@clo.cuhk.edu.hk

Key words: acquired resistance, B-cell lymphoma 2, epidermal growth factor receptor-tyrosine kinase inhibitor, non-small cell lung cancer facilitates cell proliferation, survival and invasion. In particular, EGFR-tyrosine kinase inhibitors (TKIs) have emerged as an alternative cancer treatment (2-4). Although compared to chemotherapy the outcomes of studies involving random populations are poor, TKIs elicit high response rates among NSCLC patients with EGFR mutations $(5,6)$. The Iressa Pan-Asia Study reported that NSCLC patients with EGFR mutations gained prolonged progression-free survival with gefitinib treatment compared to chemotherapy (7). However, the prognosis in patients with wild-type EGFR was improved with chemotherapy (7). EGFR can be activated with ErbB receptors, either via autocrine or paracrine ligand binding. This induces EGFR tyrosine kinase activity, which subsequently triggers downstream signaling pathways $(4,8)$. Activating mutations in EGFR are able to activate tyrosine kinase in the absence of ligands. Therefore, the downstream oncogenic signaling pathways are intrinsically upregulated (9-11).

The two most commonly observed mutations are exon 19 deletions and L858R missense substitutions at position 858 , accounting for 60 and $35 \%$ of the total cases, respectively $(12,13)$. In the presence of these mutations, the sensitivity of EGFR to EGFR-TKIs is increased and therefore these mutations are beneficial. However, a variety of treatment responses are observed and the sensitivity towards EGFR-TKIs diminished following 8-12 months of treatment $(7,10)$. This effect is primarily due to the gaining of resistance to EGFR-TKIs, either via primary resistance (de novo) or acquired resistance, following exposure to targeted agents (14). In the majority of cases, acquired resistance is due to secondary EGFR mutations (15). The most common mechanism is via gaining EGFR T790M second-site mutation, which occurs following EGFR-TKI treatment, and contributes to $\sim 50 \%$ of cases (16). The second most common mechanism involves MET amplification, which accounts for $20 \%$ of cases $(17,18)$. The remaining cases are due to mutations in phosphoinositide 3-kinase (PI3K) subunit $\alpha$, Erb-B2 receptor tyrosine kinase 2 (ERBB2; HER2), BRAF, signal transducer and activator of transcription 3, AXL receptor tyrosine kinase and the amplification of CRK like proto-oncogene adaptor protein (19-25).

Previous studies have reported that a common Bcl2-like 11 (BIM) deletion polymorphism is associated with EGFR-TKI resistance in NSCLC patients with EGFR mutations. The 
polymorphism results in alternative splicing, which leads to expression of BIM isoforms that lack a crucial pro-apoptotic Bcl2-homology domain 3 (BH3) (26). Failure to generate the functional pro-apoptotic isoform results in a drug-resistant phenotype, whereby a reduced response is observed following treatment with EGFR-TKI in patients with BMI polymorphisms vs. patients without (27). It has also been reported that BIM plays an essential role in EGFR-TKI-induced apoptosis, which may be enhanced by BH3 mimetics (28-31). Therefore, malfunction of BIM contributes considerably to the development of drug resistance. Although the precise mechanism remains to be elucidated, the MET oncogene is thought to be involved in de novo and acquired resistance to EGFR-TKI in NSCLC $(32,33)$. Acquired resistance to EGFR-TKIs is a major obstacle in the management of lung cancer; the present study was initiated to investigate insights to tackle the issue.

\section{Materials and methods}

Cell lines and patient biopsies. HCC827 was obtained from the American Type Culture Collection (Manassas, VA, USA) and four resistant cell lines [gefitinib-cultured (GR) 1 and 2, erlotinib-cultured (ER) 1 and 2] were successfully screened. The cells were screened via a gradual increase in TKI dosage with a final concentration at $10 \mu \mathrm{M}$ for 6 months. Formalin-fixed, paraffin-embedded NSCLC patient samples were obtained from the Sun Yat-sen University Cancer Center between January 2012 and December 2013 (State Key Laboratory of Oncology in South China, Collaborative Innovation Center for Cancer Medicine, Guangzhou, China). The age of the patients ranged from 43 to 71 years, with a median age of 56.5 years. The male to female sex ratio was 3:7. Ethical approval and written informed consent was obtained (Sun Yat-sen University Cancer Center Institutional Review Board; approval no. YP2013-06-06). No personal information or detailed clinical histories were disclosed.

Cytotoxicity assay. Cytotoxicity was assessed by a colorimetric assay using 3-(4,5-dimethylthiazol-2-yl)-2,5-diphenyltetrazolium bromide dissolved in dimethyl sulfoxide. Cells were plated and treated with gefitinib, erlotinib and sorafenib for $48 \mathrm{~h}$. Cell proliferation inhibition was expressed as the percentage of absorbance of control cultures and measured at $570 \mathrm{~nm}$ with a microplate reader (VICTOR ${ }^{3}$ Multilabel Reader; catalog no. 1420; PerkinElmer, Inc., Waltham, MA, USA). The half maximal inhibitory concentration $\left(\mathrm{IC}_{50}\right)$ was calculated using GraphPad PRISM software version 4.0 (GraphPad Software, Inc., La Jolla, CA, USA).

Western blot analysis. To investigate the signaling properties of the cell lines, western blotting was performed with antibodies against various targets. Total protein lysate was collected with RIPA lysis buffer (Thermo Fisher Scientific, Inc., Waltham, MA, USA) containing protease and phosphatase inhibitors (Sigma-Aldrich; Merck KGaA, Darmstadt, Germany) and quantified by BCA assay. Equal amounts of protein $(25-40 \mu \mathrm{g})$ were resolved on 10\% SDS-PAGE gels and subsequently transferred onto polyvinylidene difluoride (PVDF) membrane. The PVDF membranes were blocked with 5\% non-fat milk in TBST for $30 \mathrm{~min}$ at room temperature and subsequently incubated overnight at $4^{\circ} \mathrm{C}$ with primary antibodies of interest in 1:2,000 dilution as follows: ABCC4 (D2Q20), cat. no. 12705S; ABCG2, cat. no. 4477S; Phospho-Akt (Ser473), cat. no. 9271; Phospho-Akt (Thr308), cat. no. 9275S; Akt (pan) (11E7), cat. no. 4685; EGFR E746-A750del, cat. no. 2085; EGFR, cat. no. 2232; GAPDH, cat. no. 2118; Phospho-MET (Tyr1234/1235) (3D7), cat. no. 3129 and pTEN (138G6), cat. no. 9559 (Cell Signaling Technology, Inc., Danvers, MA, USA); Bcl-2, cat. no. ab32124 (Abcam, Cambridge, UK), MET (c-12), cat. no. sc-10 (Santa Cruz Biotechnology, Inc., Dallas, TX, USA) and horseradish peroxidase-conjugated goat anti-rabbit (cat. no. 166-2408) or goat anti-mouse (cat. no. 172-1011) secondary antibodies in 1:5,000 dilution (Bio-Rad Laboratories, Inc., Hercules, CA, USA) for $2 \mathrm{~h}$ at room temperature. The blots were developed with enhanced chemiluminescence substrate (GE Healthcare Life Sciences, Chalfont, UK) and by autoradiography.

Immunohistochemistry. Tumor specimens were collected, processed and sectioned. Pathological changes were observed by staining with haematoxylin and eosin. For Bcl 2 immunostaining, sections were de-paraffinized and rehydrated through a gradient of ethanol. The samples underwent antigen retrieval by incubating in $10 \mathrm{mM}$ of citrate buffer at $95^{\circ} \mathrm{C}$ for 20 minutes. Slides were subsequently blocked with $3 \%$ bovine serum albumin in TBST and incubated with monoclonal mouse antihuman Bcl2 (Clone 124) (cat. no. M0887;1:50; DAKO; Agilent Technologies, Inc., Santa Clara, CA) for 2 hours. After that, samples were rinsed with phosphate-buffered saline and then incubated with DAKO REAL Envision HRP antibodies (cat. no. K5007; DAKO; Agilent Technologies, Inc., Santa Clara, CA ) for 30 mins. The stain was finally visualized in brown with 3,3-diaminobenzidine (DAB) as substrate following counterstained with Mayer's hematoxylin. After mounting, images were captured under the microscope Axio Observer Z1 (Carl Zeiss, Germany).

Immunofluorescence staining. Cells were plated on a sterilized cover glass and fixed with $4 \%$ paraformaldehyde. The cells were permeabilized with $0.1 \%$ Triton X-100 and were subsequently incubated for $2 \mathrm{~h}$ at room temperature with antibody against EGFR E746-A750del (cat. no. 2085; Cell Signaling Technology, Inc.) at a dilution ratio of 1:100. EGFR exon 19-deletion staining was visualized with appropriate conjugated secondary antibodies (Alexa Fluor ${ }^{\circledR} 488$; Thermo Fisher Scientific, Inc.). Cell nuclei were visualized with DAPI stain. Finally, the cover glasses were mounted on slides by anti-fade prolonged gold media (Invitrogen; Thermo Fisher Scientific, Inc.).

Quantitative (q)PCR. The RNA levels of Bcl2 in cells with resistance to EGFR-TKI were validated by qPCR using a Bcl2 Taqman Gene Expression Assay (cat. no. Hs00608023_m1; Thermo Fisher Scientific, Inc.). The reverse transcription PCR reaction was performed using 7500 Software v2.0.6 and 7500 Real-time PCR system (Applied Biosystems; Thermo Fisher Scientific, Inc.) with the following thermocycler protocol: $50^{\circ} \mathrm{C}$ for $2 \mathrm{~min}, 95^{\circ} \mathrm{C}$ for $10 \mathrm{~min}$, and then a two-step cycle of $95^{\circ} \mathrm{C}$ for $15 \mathrm{sec}$ and $60^{\circ} \mathrm{C}$ for $60 \mathrm{sec}$, for 40 cycles. The RNA expressions of Bcl2 were normalized to the parental HCC 827 for each sample by the $2^{-\Delta \Delta C q}$ method (34). 
A

Gefitinib in HCC827 and resistant cell lines

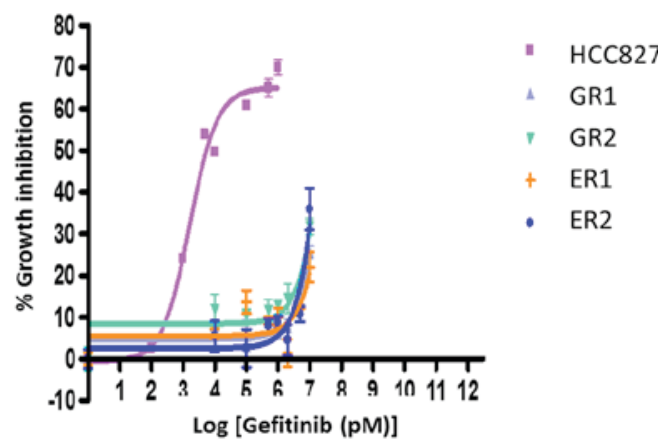

C

Sorafenib in HCC827 and resistant cell lines

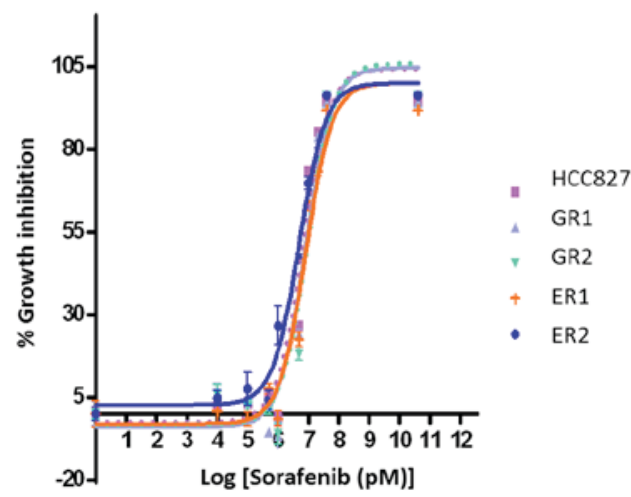

B

Erlotinib in HCC827 and resistant cell lines

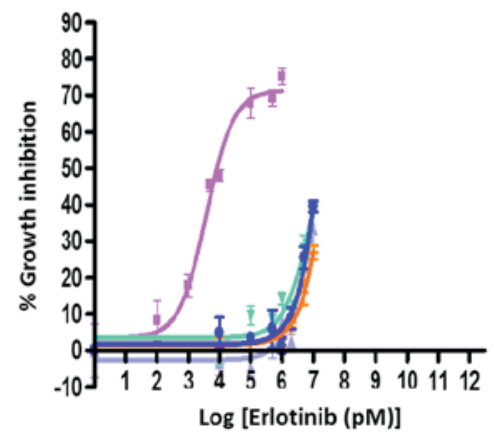

- $\mathrm{HCC} 827$

GR1

GR2

ER1

ER2

D

\begin{tabular}{lccc}
\hline Cell & \multicolumn{3}{c}{ Average IC $50(\mu \mathrm{M})$} \\
line & Gefitinib & Erlotinib & Sorafenib \\
\hline HCC827 & 0.0016 & 0.0038 & 6.8 \\
GR1 & 282.8 & 11.6 & 8.1 \\
GR2 & 238.9 & 8.7 & 9.3 \\
ER1 & 579.7 & 62.3 & 8.1 \\
ER2 & 1000 & 50.8 & 9.3 \\
\hline
\end{tabular}

Figure 1. Representative dose-response curves of HCC827 and four EGFR-TKI resistant cell lines (GR1, GR2, ER1 and ER2) at $48 \mathrm{~h}$ following incubation with: (A) Gefitinib, (B) erlotinib and (C) sorafenib. (D) Average $\mathrm{IC}_{50}$ values of growth curves. Triplicate wells were conducted for each drug concentration and the assay were repeated in $\geq 3$ independent experiments with the error bars indicating standard deviation. $\mathrm{IC}_{50}$, half maximal inhibitory concentration; EGFR-TKI, epidermal growth factor receptor-tyrosine kinase inhibitor; ER, erlotinib-cultured; GR, gefitinib-cultured.

Statistical analysis. Analyses were performed using PRISM software version 4.0 (GraphPad Software, Inc., La Jolla, CA). Unpaired t-test with Welch Correction was used unless specified. The significance of the $\mathrm{Bcl} 2 \mathrm{RNA}$ levels between resistant cell lines and parental HCC827 was determined by one-way ANOVA followed by Tukey's Honest Significant difference post-hoc test. $\mathrm{P}<0.05$ was considered to indicate a statistically significant difference.

\section{Results}

Sensitivity of the resistant cell lines to TKIs. The EGFR-mutant HCC827 is the only NSCLC cell line sensitive to EGFR-TKIs, with $\mathrm{IC}_{50}$ values of $\sim 5 \mathrm{nM}$. The cells were treated with gefitinib, erlotinib and sorafenib for $48 \mathrm{~h}$. The $\mathrm{IC}_{50}$ values of the resistant cell lines, treated with gefitinib and erlotinib, increased 1,000-fold from $1.6 \mathrm{nM}-1.0 \mathrm{mM}$ (Fig. 1A and B). The $\mathrm{IC}_{50}$ values of the cell lines treated with gefitinib were $1.6 \mathrm{nM}, 282.8,238.9$ and $579.7 \mu \mathrm{M}$ and $1.0 \mathrm{mM}$ for HCC827, GR1, GR2, ER1 and ER2, respectively. The $\mathrm{IC}_{50}$ values of the cell lines treated with erlotinib were $3.8 \mathrm{nM}$, 11.6, 8.7, 62.3 and $50.8 \mu \mathrm{M}$ for HCC827, GR1, GR2, ER1 and ER2, respectively. The sensitivity of the cell lines towards sorafenib, a specific multikinase inhibitor for vascular endothelial growth factor receptors and platelet-derived growth factor receptors, was also investigated. No statistically significant differences were observed between the parental HCC 827 cell line and the resistant clones, with $\mathrm{IC}_{50}$ values $\sim 5-10 \mu \mathrm{M}$ (Fig. 1C). The origin of the resistant clones was verified by the presence of exon 19 deletion (E746-750) in the resistant clones via immunofluorescence. This confirmed that the screened resistant clones (GR1, GR2, ER1 and ER2) originated from the parental HCC 827 cell line. The specificity of the antibody was verified by parallel testing with H358 (EGFR wild type) by western blotting (Fig. 2).

Upregulation of Bcl2 in EGFR-TKI resistant NSCLC cell line and associated signaling pathway. Strong expression of $\mathrm{Bcl} 2$ was observed in resistant clones, with the exception of ER2. Bcl2 was not detected in the parental cell line HCC827. The associated signaling pathways were investigated via western blotting. PTEN, phosphorylated (p)-MET and MET were downregulated in the resistant clones, with the exception of ER2. ER2 had similar levels of expression of PTEN, phosphorylated (p)-MET and MET proteins compared with HCC 827. Phosphorylated and un-phosphorylated forms of Akt were more strongly expressed in the resistant clones than HCC 827, as a consequence of the reduced PTEN expression in the resistant clones. Furthermore, there were no differences in expression of the drug resistant 

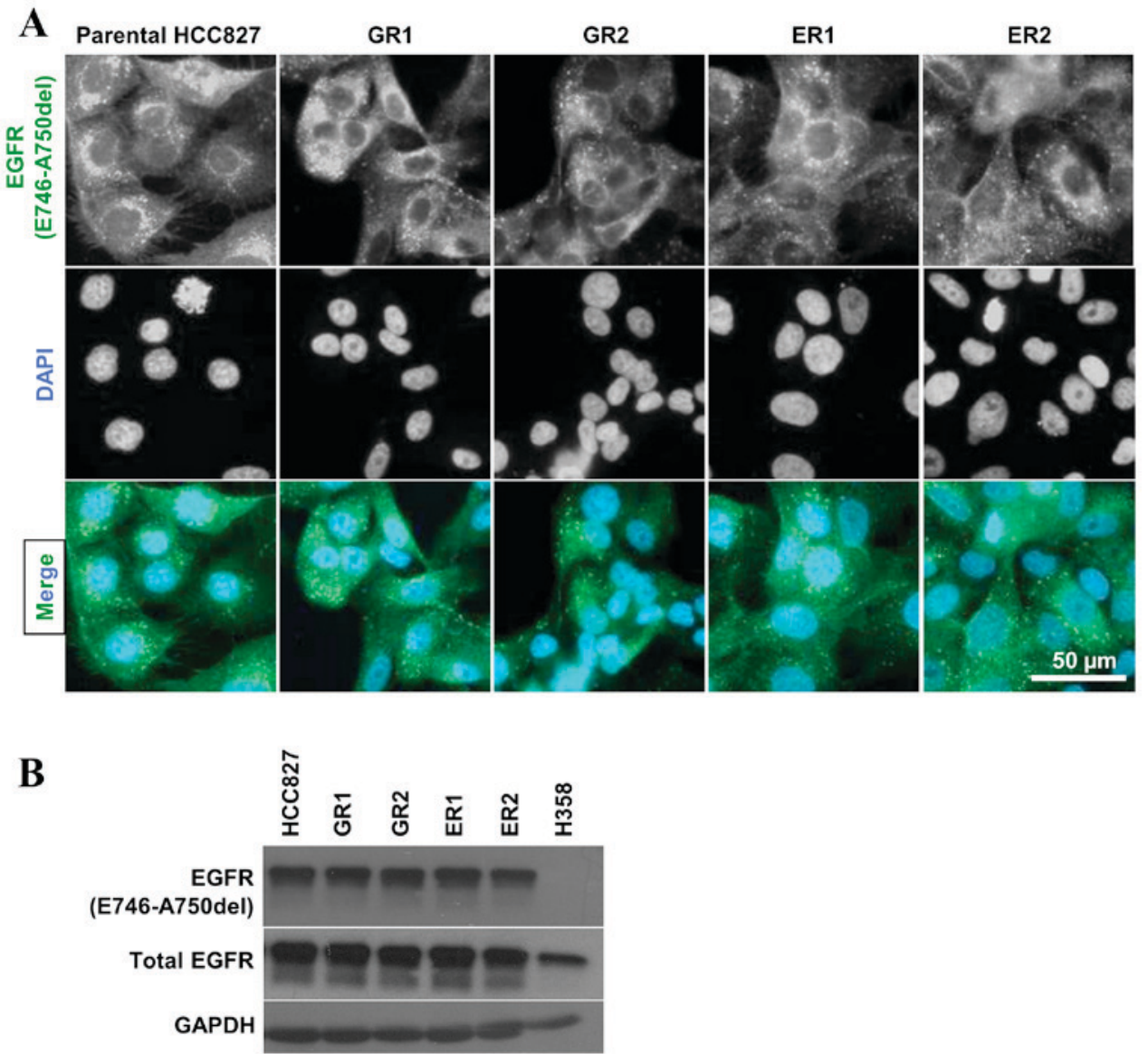

Figure 2. (A) Immunofluorescence staining of EGFR in HCC827 and four EGFR-TKI resistant cell lines (GR1, GR2, ER1 and ER2) with antibody against EGFR exon 19 deletion (E746-A750del; green) and DAPI (blue). The presence of EGFR (E746-A750del) was detected in all samples. (B) EGFR exon 19 deletion (E746-A750del) was detected by immunoblotting in HCC827, all four resistant cell lines (GR1, GR2, ER1 and ER2) and H358. Specificity of the antibody against E746-A750del was validated with H358, which served as a negative control. EGFR-TKI, epidermal growth factor receptor-tyrosine kinase inhibitor; EGFR, epidermal growth factor receptor; ER, erlotinib-cultured; GAPDH, glyceraldehyde-3-phosphate dehydrogenase; GR, gefitinib-cultured. Scale bar, $50 \mu \mathrm{m}$.

A

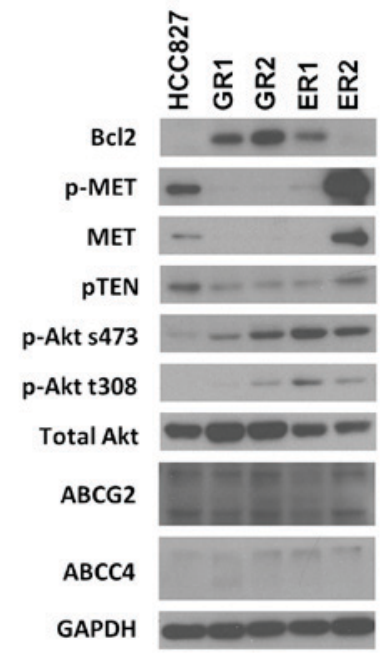

B

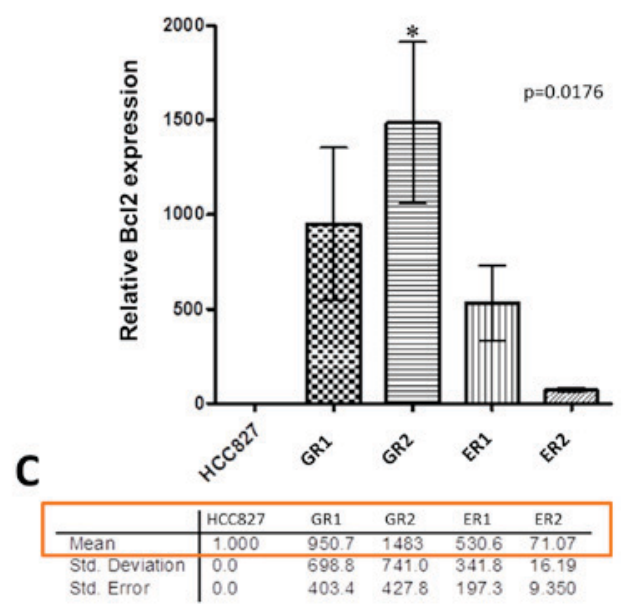

Figure 3. (A) Detection of protein expression by immunoblotting. A marked Bcl2 upregulation was observed in EGFR-TKI resistant cell lines (GR1, GR2, ER1 and ER2). (B) Bcl2 RNA expression level was quantified by qPCR and normalized to GAPDH expression with the error bars representing standard deviation. The significance of the Bcl2 RNA levels between resistant cell lines and parental HCC 827 was determined by one-way ANOVA with P=0.0176, followed by Tukey's HSD post-hoc test. "P<0.05, HCC827 vs. GR2. RNA levels of Bcl2 in resistant cell lines were 70-1,000-fold higher vs. HCC827. (C) Using parental HCC827 as the standard, the Bcl2 RNA levels were upregulated by 951-, 1,483-, 531- and 71-folds for GR1, GR2, ER1 and ER2, respectively. The $\mathrm{Bcl} 2$ level in ER2 increased by a relatively less extent compared with the other resistant clones. ABCC4, ATP-binding cassette subfamily C member 4; ABCG2, ATP-binding cassette transporter G2; EGFR-TKI, epidermal growth factor receptor-tyrosine kinase inhibitor; ER, erlotinib-cultured; GAPDH, glyceraldehyde-3-phosphate dehydrogenase; GR, gefitinib-cultured; p, phosphorylated; PTEN, phosphatase and tensin homolog; qPCR, quantitative PCR. 
A

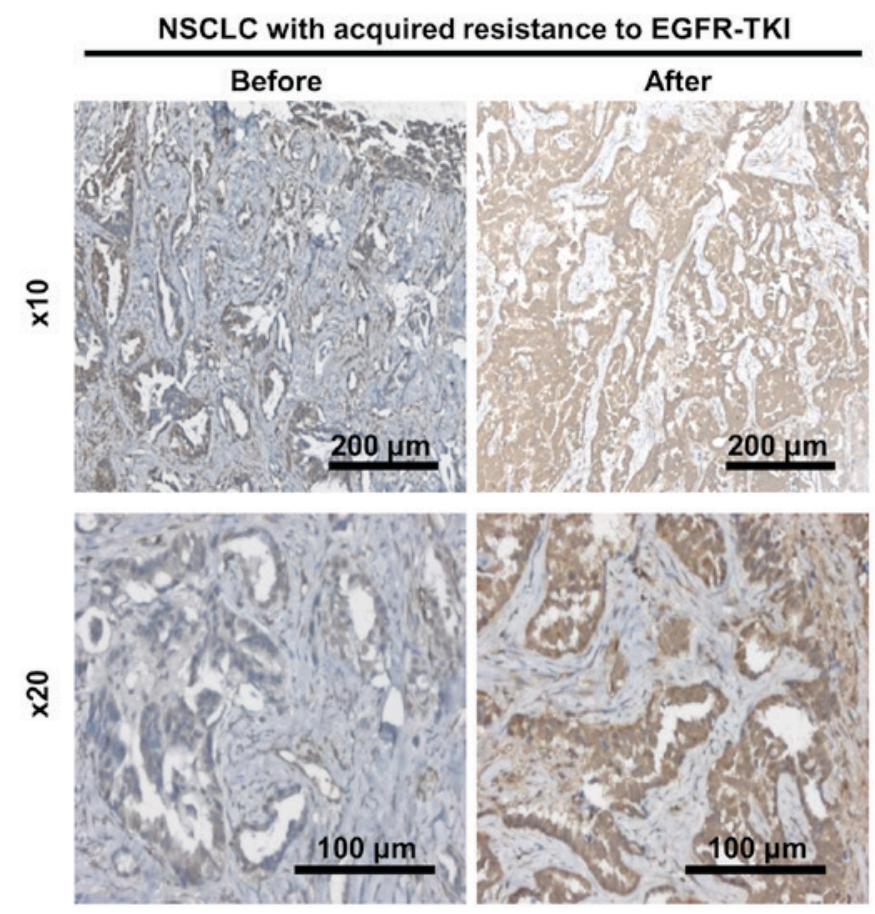

B

NSCLC with acquired resistance to EGFR-TKI

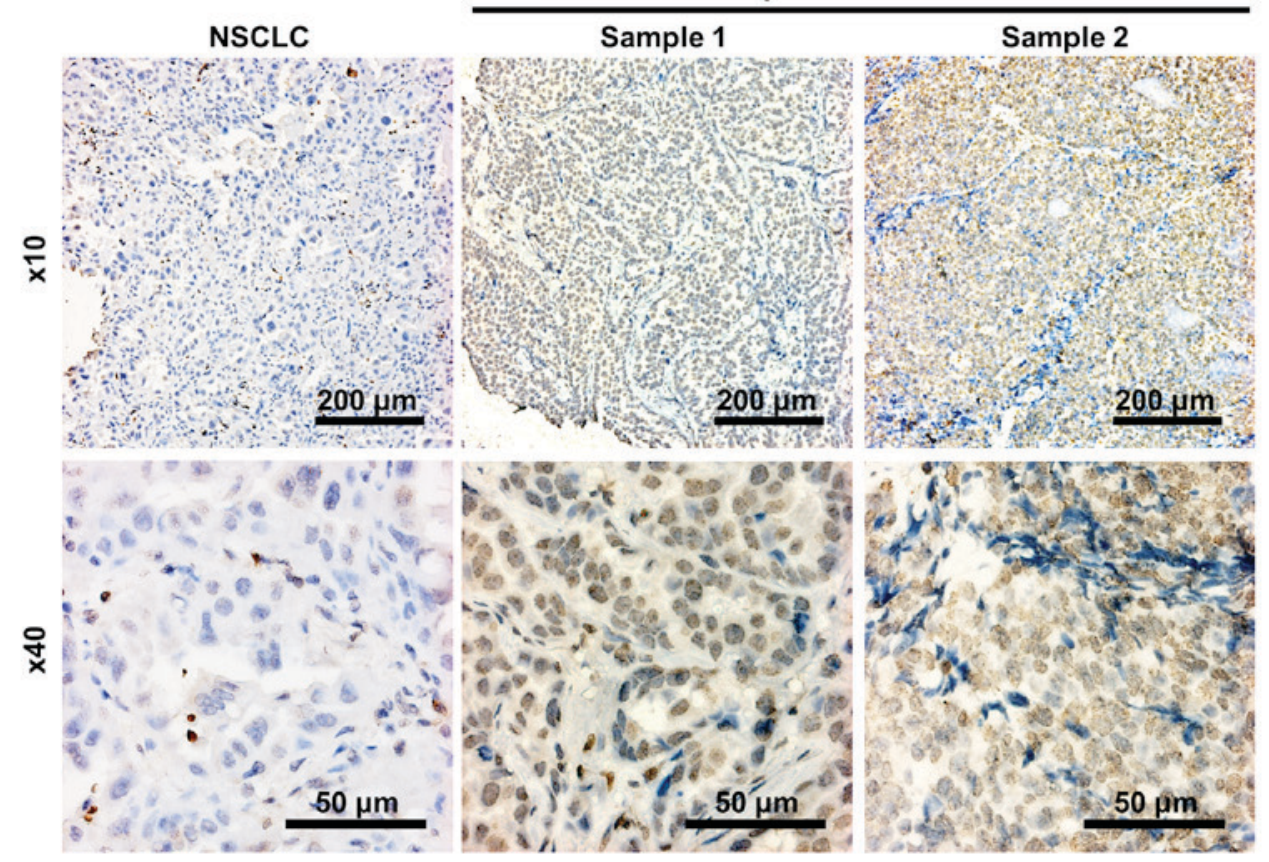

Figure 4. Immunohistochemical staining of NSCLC patient biopsies, illustrating Bcl2 expression in samples with and without resistance to EGFR-TKI. Bcl2 was strongly detected in samples with acquired resistance to EGFR-TKI, whereas it was weakly expressed in non-resistant samples. (A) Patient biopsies before and after resistance was acquired. (B) NSCLC, patient biopsies without resistance to EGFR-TKI. Samples 1 and 2, patient biopsies with acquired resistance. EGFR-TKI, epidermal growth factor receptor-tyrosine kinase inhibitor; NSCLC, non-small cell lung cancer.

pumps, ATP-binding cassette transporter $\mathrm{G} 2$ (ABCG2) and ATP-binding cassette subfamily $\mathrm{C}$ member 4 (ABCC4), in the resistant clones compared with HCC827 (Fig. 3A).

The level of Bcl2 RNA expression was examined to validate the upregulation of $\mathrm{Bcl} 2$ in resistant clones (Fig. 3B). It was observed that the levels of RNA expression of $\mathrm{Bcl} 2$ in resistant clones were 70-1,500-fold higher compared to the parental HCC827 cell line. The highest level of expression
(1,483 fold) was observed in GR2, whilst the lowest level (71 fold) was observed in ER2 (Fig. 3B). This is a potential explanation for the observation that ER2 did not resemble the other three clones as demonstrated by the western blots (Fig. 3A).

Upregulation of Bcl2 in patient biopsies in relation to TKI resistance. Small scale IHC staining was conducted on the 
NSCLC patient samples. Low levels of Bcl2 expression were detected in samples collected prior to resistance development, whereas strong levels were detected subsequent to acquiring resistance (Fig. 4A). The staining of independent samples indicated that $\mathrm{Bcl} 2$ was weakly expressed in non-resistant samples, but that it was markedly detected in resistant NSCLC samples (Fig. 4B). Together, these results provided preliminary clinical evidence to the in vitro observation that upregulation of $\mathrm{Bcl} 2$ was identified to be associated with TKI resistance.

\section{Discussion}

Lung carcinoma is an important human health issue, with respect to its high incidence and mortality rate (1). Platinum-based chemotherapy is the conventional standard treatment regime, but it has several drawbacks including limited efficacy and significant toxicity. The emergence of EGFR-TKIs signifies a remarkable breakthrough in the development of NSCLC therapeutics, particularly for patients with EGFR mutations. However, patients who initially respond to EGFR-TKIs develop resistance following varying periods of time on account of heterogeneous responses to TKIs $(14,15)$. Secondary mutations are closely associated with the development of drug resistance. Great interest has been generated in overcoming this impediment in the management of lung cancer $(35,36)$.

BIM deletion polymorphisms were reported to be one of the molecular mechanisms contributing to intrinsic EGFR-TKI resistance (26). BIM is a proapoptotic member of the $\mathrm{Bcl} 2$ family, encoding gene products with a BH3 domain, including $\mathrm{BIM}_{\mathrm{EL}}, \mathrm{BIM}_{\mathrm{L}}$ and $\mathrm{BIM}_{\mathrm{S}}$, which are essential elements for inducing apoptosis, activating proapoptotic and antagonizing antiapoptotic proteins (37-39). The deletion polymorphism switches BIM splicing from exon 4 to exon 3, which generates BIM isoforms that lack the $\mathrm{BH} 3$ domain, resulting in a diminished ability to trigger cell death (27).

In the present study, four $\mathrm{HCC} 827$ resistant cell lines were screened successfully by inducing mild selection pressure; GR1 and GR2 were screened with gefitinib, while ER1 and ER2 were screened with erlotinib. The resistant cell lines were shown to be highly insensitive to EGFR-TKIs, with the $\mathrm{IC}_{50}$ values against EGFR-TKIs 1,000-fold higher than the parental HCC 827 cell line. The results indicated a cross-resistance across the same TKI family, as GR and ER cell lines demonstrated high tolerance to erlotinib. Furthermore, the gaining of acquired resistance did not alter the sensitivity of cells against TKIs of other families e.g., sorafenib.

The resistance mechanism of the parental and resistant cell lines was investigated by examining their signaling pathways. The results illustrated a marked upregulation of $\mathrm{Bcl} 2 \mathrm{in}$ resistant clones, which has not been previously reported in EGFR-TKI acquired resistance. RNA expression of the resistant cell lines further confirmed that Bcl2 was markedly upregulated. Furthermore, the resistance was not due to ATP-binding cassette (ABC) multidrug transporters, as the western blots showed no effects on ABCG2 and ABCC4 proteins. These proteins were detected in patients undergoing chemotherapy, and shown to confer resistance against cytotoxic compounds applied in cancer therapy by blocking the drugs from reaching intracellular targets (40-42). This further confirmed the role of aberrant BIM function on acquired resistance to EGFR-TKI.
MET amplification also contributes to the development of acquired resistance to EGFR-TKI by activating PI3K/Akt signaling through ERBB3 (32). It was reported that MET, EGFR, ERBB2 and ERBB3 were all phosphorylated in parental cell lines and the proteins were reduced upon gefitinib treatment. Downregulation of the ERBB3/PI3K/Akt signaling axis leads to the induction of apoptosis. By contrast, high levels of phosphorylation remained in the resistant cells in the presence of gefitinib, which caused little or no apoptotic effect $(32,43)$. Based on the results, phosphorylation of MET was reduced in GR1, GR2 and ER1, whilst phosphorylation of Akt was increased. Meanwhile, PTEN expression was decreased in accordance with the level of Akt phosphorylation. The hypothesis that $\mathrm{Bcl}-2$ is a contributing factor to the EGFR-TKI-acquired resistant was further supported by immunohistochemical staining of $\mathrm{Bcl} 2$ on patient biopsies. This implied that MET amplification may not be a potential mechanism of acquired resistance, PTEN and Bcl2 are more likely to be contributing factors of acquired resistance, meaning that the resistance mechanism is potentially pathway-specific.

In conclusion, EGFR-TKI acquired resistance is a major obstacle in lung cancer therapy. The results of the present study provide evidence that upregulation of Bcl2 may be a latent driver for resistance exploitation. This warrants further investigation in targeting $\mathrm{Bcl} 2$ as a strategy in treating NSCLC with acquired resistance.

\section{Acknowledgements}

The authors would like to thank the Charlie Lee Charitable Foundation (Hong Kong, Hong Kong, SAR, P.R. China) for their support.

\section{References}

1. Ferlay J, Soerjomataram I, Dikshit R, Eser S, Mathers C, Rebelo M, Parkin DM, Forman D and Bray F: Cancer incidence and mortality worldwide: Sources, methods and major patterns in GLOBOCAN 2012. Int J Cancer 136: E359-E386, 2015.

2. Hotta K, Fujiwara Y, Matsuo K, Suzuki T, Kiura K, Tabata M, Takigawa N, Ueoka H and Tanimoto M: Recent improvement in the survival of patients with advanced nonsmall cell lung cancer enrolled in phase III trials of first-line, systemic chemotherapy. Cancer 109: 939-948, 2007.

3. Peters S, Adjei AA, Gridelli C, Reck M, Kerr K and Felip E; ESMO Guidelines Working Group: Metastatic non-small-cell lung cancer (NSCLC): ESMO Clinical Practice Guidelines for diagnosis, treatment and follow-up. Ann Oncol 23 (Suppl 7): vii56-vii64, 2012.

4. Arteaga CL: The epidermal growth factor receptor: From mutant oncogene in nonhuman cancers to therapeutic target in human neoplasia. J Clin Oncol 19 (18 Suppl): 32S-40S, 2001.

5. Gatzemeier U, Pluzanska A, Szczesna A, Kaukel E, Roubec J, De Rosa F, Milanowski J, Karnicka-Mlodkowski H, Pesek M, Serwatowski P, et al: Phase III study of erlotinib in combination with cisplatin and gemcitabine in advanced non-small-cell lung cancer: The Tarceva Lung Cancer Investigation Trial. J Clin Oncol 25: 1545-1552, 2007.

6. Herbst RS, Prager D, Hermann R, Fehrenbacher L, Johnson BE, Sandler A, Kris MG, Tran HT, Klein P, Li X, et al: TRIBUTE: A phase III trial of erlotinib hydrochloride (OSI-774) combined with carboplatin and paclitaxel chemotherapy in advanced non-small-cell lung cancer. J Clin Oncol 23: 5892-5899, 2005.

7. Mok TS, Wu YL, Thongprasert S, Yang CH, Chu DT, Saijo N, Sunpaweravong P, Han B, Margono B, Ichinose Y, et al: Gefitinib or carboplatin-paclitaxel in pulmonary adenocarcinoma. N Engl J Med 361: 947-957, 2009. 
8. Wilson KJ, Gilmore JL, Foley J, Lemmon MA and Riese DJ II: Functional selectivity of EGF family peptide growth factors: Implications for cancer. Pharmacol Ther 122: 1-8, 2009.

9. Laurent-Puig P, Lievre A and Blons H: Mutations and response to epidermal growth factor receptor inhibitors. Clin Cancer Res 15: 1133-1139, 2009.

10. Kancha RK, von Bubnoff N, Peschel C and Duyster J: Functional analysis of epidermal growth factor receptor (EGFR) mutations and potential implications for EGFR targeted therapy. Clin Cancer Res 15: 460-467, 2009

11. Sharma SV, Bell DW, Settleman J and Haber DA: Epidermal growth factor receptor mutations in lung cancer. Nat Rev Cancer 7: 169-181, 2007.

12. Jackman DM, Yeap BY, Sequist LV, Lindeman N, Holmes AJ, Joshi VA, Bell DW, Huberman MS, Halmos B, Rabin MS, et al: Exon 19 deletion mutations of epidermal growth factor receptor are associated with prolonged survival in non-small cell lung cancer patients treated with gefitinib or erlotinib. Clin Cancer Res 12: 3908-3914, 2006.

13. Rosell R, Moran T, Queralt C, Porta R, Cardenal F, Camps C, Majem M, Lopez-Vivanco G, Isla D, Provencio M, et al Screening for epidermal growth factor receptor mutations in lung cancer. N Engl J Med 361: 958-967, 2009.

14. Jackman D, Pao W, Riely GJ, Engelman JA, Kris MG, Jänne PA Lynch T, Johnson BE and Miller VA: Clinical definition of acquired resistance to epidermal growth factor receptor tyrosine kinase inhibitors in non-small-cell lung cancer. J Clin Oncol 28 : 357-360, 2010

15. Pao W, Miller VA, Politi KA, Riely GJ, Somwar R, Zakowski MF, Kris MG and Varmus H: Acquired resistance of lung adenocarcinomas to gefitinib or erlotinib is associated with a second mutation in the EGFR kinase domain. PLoS Med 2: e73, 2005.

16. Sun JM, Ahn MJ, Choi YL, Ahn JS and Park K: Clinical implications of T790M mutation in patients with acquired resistance to EGFR tyrosine kinase inhibitors. Lung Cancer 82: 294-298, 2013.

17. Ayoola A, Barochia A, Belani K and Belani CP: Primary and acquired resistance to epidermal growth factor receptor tyrosine kinase inhibitors in non-small cell lung cancer: An update. Cancer Invest 30: 433-446, 2012.

18. Bean J, Brennan C, Shih JY, Riely G, Viale A, Wang L, Chitale D, Motoi N, Szoke J, Broderick S, et al: MET amplification occurs with or without T790M mutations in EGFR mutant lung tumors with acquired resistance to gefitinib or erlotinib. Proc Natl Acad Sci USA 104: 20932-20937, 2007.

19. Ohashi K, Sequist LV, Arcila ME, Moran T, Chmielecki J, Lin YL, Pan Y, Wang L, de Stanchina E, Shien K, et al: Lung cancers with acquired resistance to EGFR inhibitors occasionally harbor BRAF gene mutations but lack mutations in KRAS NRAS, or MEK1. Proc Natl Acad Sci USA 109: E2127-E2133, 2012.

20. Sequist LV, Waltman BA, Dias-Santagata D, Digumarthy S, Turke AB, Fidias P, Bergethon K, Shaw AT, Gettinger S, Cosper AK, et al: Genotypic and histological evolution of lung cancers acquiring resistance to EGFR inhibitors. Sci Transl Med 3: 75ra26, 2011.

21. Serizawa M, Takahashi T, Yamamoto N and Koh Y: Genomic aberrations associated with erlotinib resistance in non-small cell lung cancer cells. Anticancer Res 33: 5223-5233, 2013.

22. Takezawa K, Pirazzoli V, Arcila ME, Nebhan CA, Song X, de Stanchina E, Ohashi K, Janjigian YY, Spitzler PJ, Melnick MA, et al: HER2 amplification: A potential mechanism of acquired resistance to EGFR inhibition in EGFR mutant lung cancers that lack the second-site EGFRT790M mutation. Cancer Discov 2: 922-933, 2012.

23. Wu K, Chang Q, Lu Y, Qiu P, Chen B, Thakur C, Sun J, Li L, Kowluru A and Chen F: Gefitinib resistance resulted from STAT3-mediated Akt activation in lung cancer cells. Oncotarget 4: 2430-2438, 2013.

24. Yu HA, Arcila ME, Rekhtman N, Sima CS, Zakowski MF Pao W, Kris MG, Miller VA, Ladanyi M and Riely GJ: Analysis of tumor specimens at the time of acquired resistance to EGFR TKI therapy in 155 patients with EGFR mutant lung cancers. Clin Cancer Res 19: 2240-2247, 2013

25. Zhang Z, Lee JC, Lin L, Olivas V, Au V, LaFramboise T, Abdel-Rahman M, Wang X, Levine AD, Rho JK, et al: Activation of the AXL kinase causes resistance to EGFR-targeted therapy in lung cancer. Nature Genet 44: 852-860, 2012.
26. Ng KP, Hillmer AM, Chuah CT, Juan WC, Ko TK, Teo AS, Ariyaratne PN, Takahashi N, Sawada K, Fei Y, et al: A common BIM deletion polymorphism mediates intrinsic resistance and inferior responses to tyrosine kinase inhibitors in cancer. Nat Med 18: 521-528, 2012.

27. Nakagawa T, Takeuchi S, Yamada T, Ebi H, Sano T, Nanjo S, Ishikawa D, Sato M, Hasegawa Y, Sekido Y and Yano S: EGFR-TKI resistance due to BIM polymorphism can be circumvented in combination with HDAC inhibition. Cancer Res 73: 2428-2434, 2013.

28. Costa DB, Halmos B, Kumar A, Schumer ST, Huberman MS, Boggon TJ, Tenen DG and Kobayashi S: BIM mediates EGFR tyrosine kinase inhibitor-induced apoptosis in lung cancers with oncogenic EGFR mutations. PLoS Med 4: 1669-1680, 2007.

29. Cragg MS, Kuroda J, Puthalakath H, Huang DC and Strasser A: Gefitinib-induced killing of NSCLC cell lines expressing mutant EGFR requires BIM and can be enhanced by $\mathrm{BH} 3$ mimetics. PLoS Med 4: 1681-1690, 2007.

30. Faber AC, Corcoran RB, Ebi H, Sequist LV, Waltman BA, Chung E, Incio J, Digumarthy SR, Pollack SF, Song Y, et al: BIM expression in treatment-naive cancers predicts responsiveness to kinase inhibitors. Cancer Discov 1: 352-365, 2011.

31. Gong Y, Somwar R, Politi K, Balak M, Chmielecki J, Jiang X and Pao W: Induction of BIM is essential for apoptosis triggered by EGFR kinase inhibitors in mutant EGFR-dependent lung adenocarcinomas. PLoS Med 4: e294, 2007.

32. Engelman JA, Zejnullahu K, Mitsudomi T, Song Y, Hyland C, Park JO, Lindeman N, Gale CM, Zhao X, Christensen J, et al: MET amplification leads to gefitinib resistance in lung cancer by activating ERBB3 signaling. Science 316: 1039-1043, 2007.

33. Benedettini E, Sholl LM, Peyton M, Reilly J, Ware C, Davis L, Vena N, Bailey D, Yeap BY, Fiorentino M, et al: Met activation in non-small cell lung cancer is associated with de novo resistance to EGFR inhibitors and the development of brain metastasis. Am J Pathol 177: 415-423, 2010.

34. Livak KJ and Schmittgen TD: Analysis of relative gene expression data using real-time quantitative PCR and the 2(-Delta Delta C(T)) method. Methods 25: 402-408, 2001

35. Balak MN, Gong Y, Riely GJ, Somwar R, Li AR, Zakowski MF, Chiang A, Yang G, Ouerfelli O, Kris MG, et al: Novel D761Y and common secondary T790M mutations in epidermal growth factor receptor-mutant lung adenocarcinomas with acquired resistance to kinase inhibitors. Clin Cancer Res 12: 6494-6501, 2006.

36. Kosaka T, Yatabe Y, Endoh H, Yoshida K, Hida T, Tsuboi M, Tada H, Kuwano $\mathrm{H}$ and Mitsudomi T: Analysis of epidermal growth factor receptor gene mutation in patients with non-small cell lung cancer and acquired resistance to gefitinib. Clin Cancer Res 12: 5764-5769, 2006.

37. Chen L, Willis SN, Wei A, Smith BJ, Fletcher JI, Hinds MG, Colman PM, Day CL, Adams JM and Huang DC: Differential targeting of prosurvival $\mathrm{Bcl}-2$ proteins by their $\mathrm{BH} 3$-only ligands allows complementary apoptotic function. Mol Cell 17: 393-403, 2005.

38. O'Connor L, Strasser A, O'Reilly LA, Hausmann G, Adams JM, Cory S and Huang DC: Bim: A novel member of the Bcl-2 family that promotes apoptosis. EMBO J 17: 384-395, 1998

39. Youle RJ and Strasser A: The BCL-2 protein family: Opposing activities that mediate cell death. Nat Rev Mol Cell Biol 9: 47-59, 2008.

40. Özvegy-Laczka C, Cserepes J, Elkind NB and Sarkadi B: Tyrosine kinase inhibitor resistance in cancer: Role of ABC multidrug transporters. Drug Resist Updat 8: 15-26, 2005.

41. Jonker JW, Buitelaar M, Wagenaar E, Van Der Valk MA, Scheffer GL, Scheper RJ, Plosch T, Kuipers F, Elferink RP, Rosing $\mathrm{H}$, et al: The breast cancer resistance protein protects against a major chlorophyll-derived dietary phototoxin and protoporphyria. Proc Natl Acad Sci USA 99: 15649-15654, 2002.

42. Allen JD and Schinkel AH: Multidrug resistance and pharmacological protection mediated by the breast cancer resistance protein (BCRP/ABCG2). Mol Cancer Ther 1: 427-434, 2002

43. Engelman JA, Jänne PA, Mermel C, Pearlberg J, Mukohara T, Fleet C, Cichowski K, Johnson BE and Cantley LC: ErbB-3 mediates phosphoinositide 3-kinase activity in gefitinib-sensitive non-small cell lung cancer cell lines. Proc Natl Acad Sci USA 102: 3788-3793, 2005

This work is licensed under a Creative Commons

Attribution-NonCommercial-NoDerivatives 4.0 International (CC BY-NC-ND 4.0) License. 